
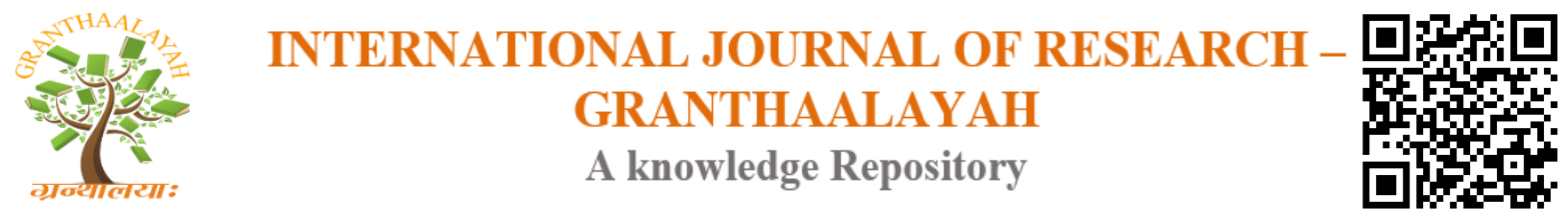

Science

\title{
NEW RULES FOR THE FOUR SEASONS OF THE YEAR IN COUNTRIES FROM TROPICAL ZONE
}

\author{
Luiz Sampaio Athayde Junior *1 \\ ${ }^{* 1}$ UNIRB, Faculty - Accounting and Management, Brazil
}

\begin{abstract}
The main proposal of this text is the recognition of the new seasons of the year for tropical countries. In the textbooks of tropical countries we teaches and learns the seasons as if they were temperate zone countries. As this content was created in the temperate zone, or more precisely in Europe, the processes of colonization of the tropical countries practiced by European countries, only means that this content is repeated even if it is not correct and even if it does not make any practical sense there. Besides the scientific misunderstanding, it is necessary to correct through education the periods and calendars of the four seasons of the countries of the tropical zone. The cultural issues of each locality should be taken into account without the simplification that there is no winter in the tropics or there is summer throughout the all year long. The region is large enough to house different proposals for locations with different climatic characteristics. We should not only use international conventions as if all regions of the planet had identical characteristics. Obviously, just as in the tropical zone things are different from the temperate zone, certainly in the polar zones things as different that two first. With the current speed and flow of information does not justify using an international convention that does not portray the reality of our country.
\end{abstract}

Keywords: Four Seasons; New Four Seasons; New Four Seasons in Tropics; Tropical Astronomy; The Solar Zenith Theory; Paradoxical Variation of Solar Day.

Cite This Article: Luiz Sampaio Athayde Junior. (2019). "NEW RULES FOR THE FOUR SEASONS OF THE YEAR IN COUNTRIES FROM TROPICAL ZONE." International Journal of Research - Granthaalayah, 7(6), 241-247. 10.29121/granthaalayah.v7.i6.2019.801.

\section{Introduction}

The seasons occur across the planet because of the inclination of its longitudinal imaginary axis. The translation of the earth shows the four different astronomical positions, which help to define the four seasons, lasting $~ 90$ days each. The four seasons are set also by weather patterns and the incidence of the sun throughout the year in the tropical zone, it makes the differences become more subtle, and damaging its conceptualization in this region.

Their differences are more bounded outside the tropics, in the temperate zone, in the dominant countries, which have created these rules and imposed through literature for northern colonized 
countries such as ours. The dominant countries in the world are United States of America, Japan and Countries from European Continent.

Brazil it's a country colonized for Portuguese people and others countries from South and Central America (tropical America) was colonized for Spanish people. Spain and Portugal are countries from European continent. Besides being an almost totally tropical country, Brazil is the only country in the world in whose territory are Equator and one of the Tropics, The Tropic of Capricorn. This differentiated condition in relation to the countries of the temperate zone in itself justifies the adoption of it's own rules for four seasons, but we only learn and teach the four seasons like countries from temperate zone, even it's no make sense here.

\section{Materials and Methods}

The sun towards on Salvador $27 / 10$ (Bahia, Brazil), for example, far before the official summer (almost 60 days), therefore, the city receives its rays back the pin, $\sim 15 / 02$, which would date the fall in the official rules. The summer of Salvador should be considered on 27/10, date of the first solar zenith until April 2nd, 45 days after the second, because the heat comes before summer officially and lasts much longer, with high temperatures since before Spring official until after the official fall, which would justify the modification.

Solar Zenith in Salvador

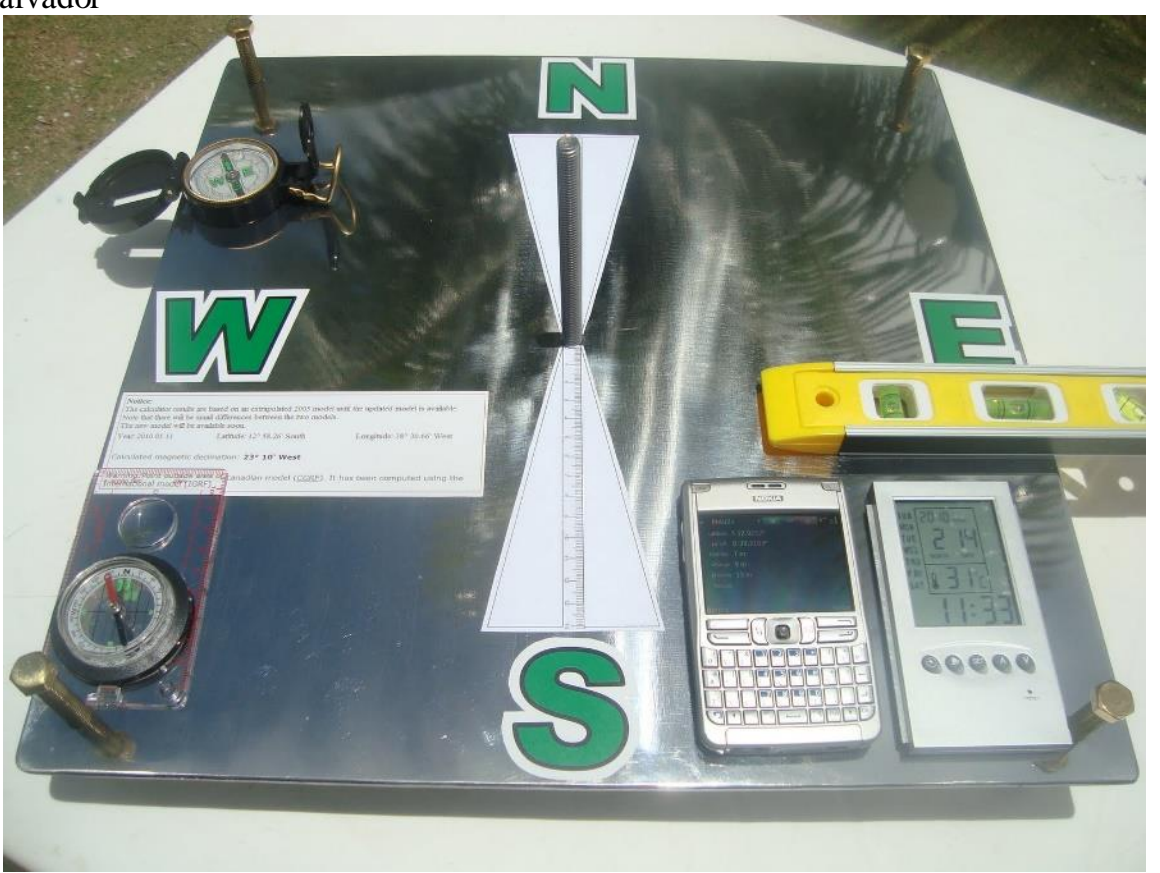

Source: veraodabahia.blogspot.com $(\mathrm{Own})^{1}$

A metal plate contains a central gnomon done with a screw length of $120 \mathrm{~mm}$. It also has four screws at their ends to allow a perfect leveling, which is measured by the level, which also equips

\footnotetext{
${ }^{1}$ Obviously there are a lot of images in blog veraodabahia.blogspot.com In this text, only one was chosen so as not to make the text too long.
} 
the board, and other equipment needed as a global positioning device - GPS, compass and a clock with thermometer and calendar.

The image shows the GPS geographical coordinates of Salvador, the calendar shows that the image was made on 14/02/2010, so a date zenith in Salvador and the clock shows that were 11:33 am, just before the occurrence of perfect zenith what can be perceived by the shadow cast westbound. Compasses placed on the board make the same is perfectly aimed at the geographic North, given the discount of the local magnetic declination, informed by a constant adhesive plate.

The differentiated system of direct sunlight, twice a year between the tropics, highlighting the need for different standards for four seasons of the year in these localities are, however, it is taught the same rules of the temperate zone.

Different society need different types of education as long as it is taught by the master minds of education. Knowledge acquisition will make by the subject's interaction with the environment, and knowledge is built with the approximation of reality by men, therefore, would be more correct to teach rules that are consistent with the observed reality in different localities, especially with the possibility of flowing information, update observation, and the presence of new technologies available for education.

There is another concept in temperate zone totally incorrect in tropical zone. In the summer, the day are more longer than night, and in the winter, the night are more longer than day. In fact, this phenomenon is bigger in polos of the earth and have well observation in temperate zone, but in our latitude, 13.0 degrees south (Salvador, Bahia, Brazil), we can observer the variations of velocity of the sun but not the variation duration of the day and night because changes summer to winter. There some days that the sunset and sunrise happen early and other that it happens latest. This variations of velocity happen four times a year and can be demonstrate by the sun's analemma. It's already was demonstrate in a conference in Houston, last 2015 in a text entitled Paradoxical Variation of the Solar Day Related to Kepler/Newton System. This speed variations of the solar day do not happen in relation by velocity variation of the planet in your own orbit. Are different phenomenon and have different causes. ${ }^{2}$

\section{Results and Discussions}

For this reason, the summer in Salvador should be considered since the first solar zenith $(\sim 27 / 10)$ until 45 days after the second zenith ( 15/02). From 25/07 to 03/11 the sunset become more fast, and sunset happen each day early. $27 / 10$ it's a date next to $03 / 11$, the fastest day of the sun in tropical zone. We observer high temperatures this date. For the same reason (see sun's analemma and calendar), 12/02 it's the slowest day by solar day. Sunset late. If sun stay more time, we can considered summer after solar zenith more 45 days at least. It's a careful criteria because a official season is 90 days long.

\footnotetext{
${ }^{2}$ The text can be found here: https://www.longdom.org/open-access/paradoxical-variation-of-the-solar-day- relatedto-keplernewton-system-2168-9792-1000145.pdf
} 
Solar Analema Map

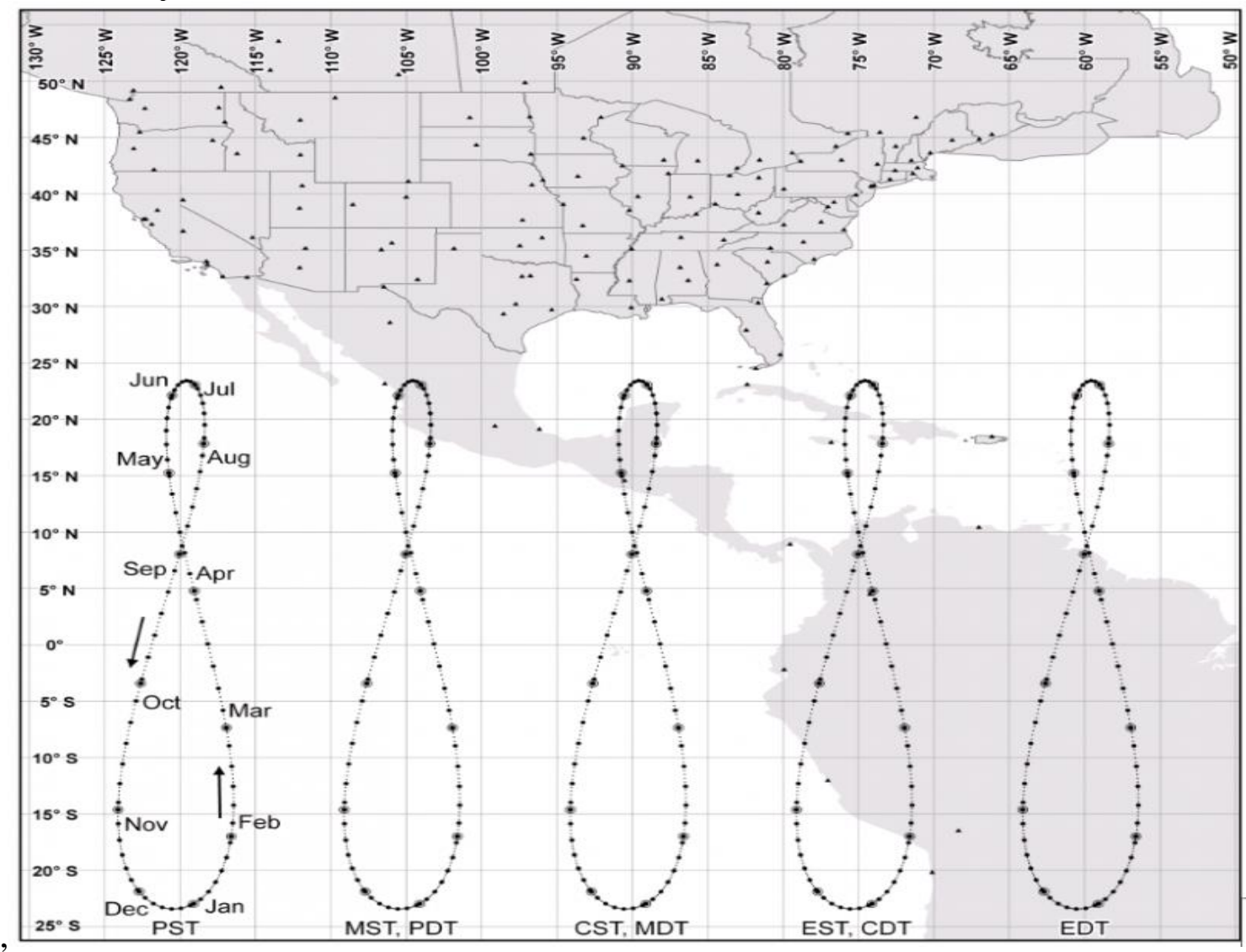

Source: Center for Geographic Analysis - Harvard University

Obviously other locations from tropical zone can considerer it own seasons based in solar zenith and climatic parameters. Certainly we need to create a new tropical zone in two parts in each hemisphere. From point of latitude $11^{\circ} 43^{\prime} 11^{\prime \prime}$ until the tropic (the mid distance between equator and tropic, north or south) we have bigger summer, at least zenith to zenith more 45 days, as decribed. It's necessary remember that in south the difference between points of the analemma are bigger than in north. Probably from point of latitude $11^{\circ} 43^{\prime} 11^{\prime \prime}$ until the equator (the mid distance between equator and tropic, north or south) there aren't winter.

We should to listen to the consideration of the scientists living in those localities before to confirm such scientific dictates. Just as it is a mistake to try to impose the seasons of the temperate zone there, it would also be wrong to try to impose a rule on a latitude based on the parameters of another. 
On World Map Showing Equator

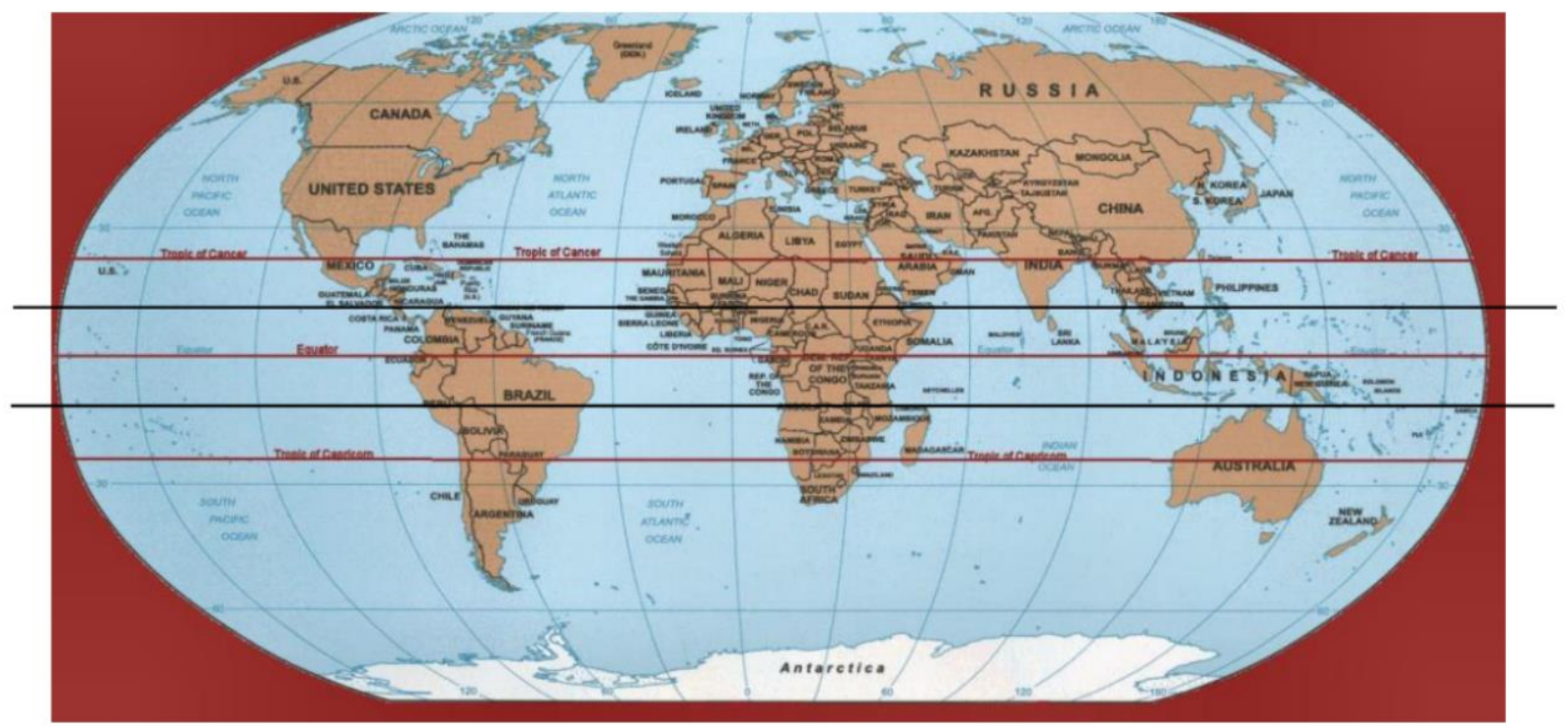

Source: picturetomorrow.org

In addition, it is necessary to remember that the summer of the southern hemisphere occurs near the perihelion, which makes it more intense than that of the northern hemisphere, which occurs near aphelion. Obviously this makes, by analogy, that the winter of the northern hemisphere is stricter than that of the southern hemisphere. On these differences it is possible to demonstrate a point of coincidence. The point of the perihelion in the analemma occurs $\sim 14$ days after the southern solstice and the same occurs in the north. The point of aphelion in the analemma occurs $\sim 14$ days after the northern solstice.

Special Points in Analemma

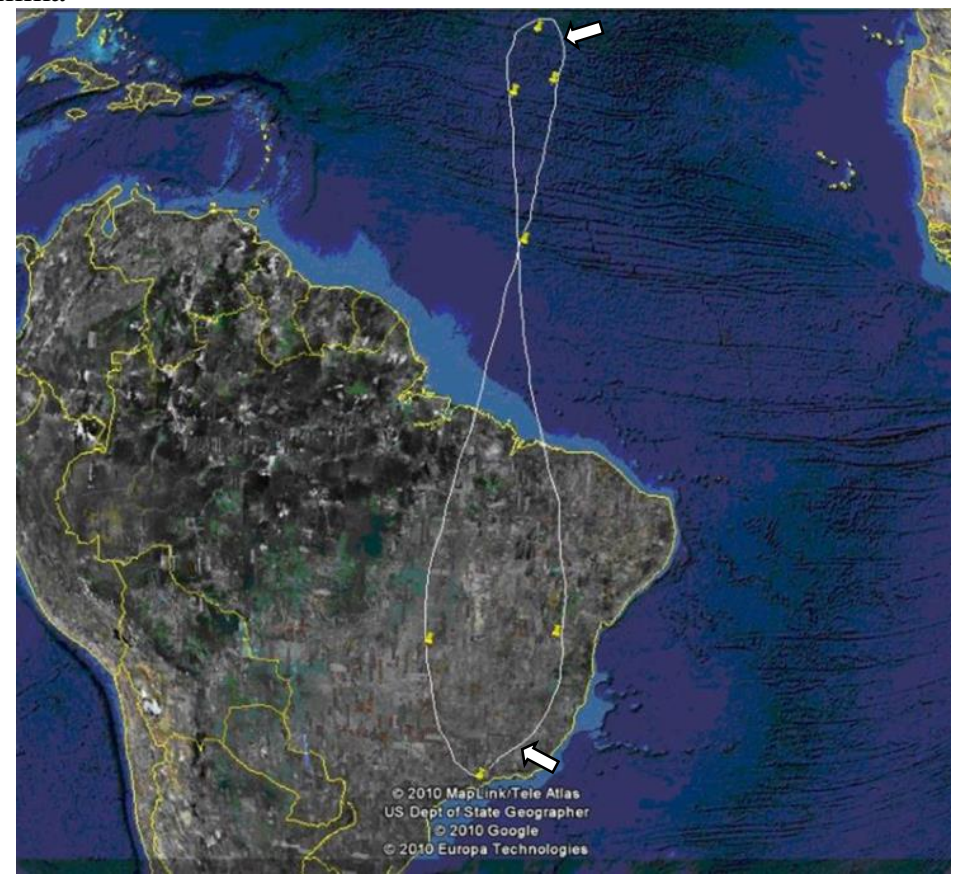

Source: Paradoxical Variation of the Solar Day Related to Kepler/Newton System (Own) 


\section{Conclusions and Recommendations}

It is perfectly possible that the Seasons of the Year can not be measured with such precision of dates in all locations of the same latitude because there are certainly different climatic factors at different locations. It is perfectly possible also that there are differences between what should be the durations of summer and winter if we compare the localities of the north and the south because of the differences of distance of the planet with respect to the sun when it is summer or winter in the north or the south, as described.

What is unacceptable is that, having this knowledge about the planet and its movements it is necessary to repeat only the four Seasons of The Year as described in the temperate zone as if it were correct for the entire planet. In tropical locality things are different and the dates set by the four astronomical positions of the planet are not always in line with the realities of many places in tropical countries.

For Salvador the summer should be started on October 27, its zenith solar date, and do not wait until December 21 when the sun is in the tropic of capricorn. Summer should last until April 02, 45 days after the second solar zenith (which occurs on February 12), then we will divide the rest of the year ( seven months) into the other three seasons, fall, winter and spring, which would be shorter than in temperate zone countries.

As the four names of the seasons are very traditionally known and rooted in culture and education, we must continue to use them. The other tropical locations should decide the durations of their seasons based on solar zenith and their climatic factors.

\section{References}

[1] ATHAYDE JUNIOR, Luiz Sampaio. Paradoxical Variation of the Solar Day Related to Kepler/Newton System. [2015]. Available in:

$<$ https://www.longdom.org/open-access/paradoxical-variation-of-the-solar-day-related-tokeplernewton-system-2168-9792-1000145.pdf>. Access: 21 jun. 2019.

[2] ATHAYDE JUNIOR, Luiz Sampaio. The Theory Of Solar Zenith. Available in: <https://www.morebooks.de/store/gb/book/the-theory-of-solar-zenith/isbn/978- 3-659-83760-9>. Access: 03 jul. 2019. More Books. Berlim, 2016.

[3] ATHAYDE JUNIOR, Luiz Sampaio. Verão da Bahia. [2009]. Available in: <http://www.veraodabahia.blogspot.com.br>. Access: 21 jun. 2019.

[4] BLOSSOM, Jeff; SADLER, Phillip. Solar Analema Map. Available in: 〈http://gis2.harvard.edu/services/project-consultation/project-resume/solar-analema-map〉. Center for Geographic Analysis / Harvard University. Access: 03 jul. 2019.

[5] OLIVEIRA FILHO, Kepler de Souza; SARAIVA, Maria de Fátima Oliveira. Movimento anual do sol e as estações do ano. 2012. Available in: <http://astro.if.ufrgs.br/tempo/mas.htm>. Access: 20 mar. 2019.

[6] SUN Motions Demonstrator - Nebraska Astronomy Applet Project - NAAP - Universidade de Nebraska-Lincoln - UNL. 2009. Available in:

<http://veraodabahia.blogspot.com.br/2009_05_01_archive.html>. (Own). Access: 03 jul. 2019. (Translated Version to Portuguese). 


\section{About Author}

Luiz Sampaio Athayde Junior, natural from Feira de Santana city, Bahia - Brazil, holds a Master's Degree in Business Administration (2010) and also Extension in Higher Education Methodology (2006) by the Administration School of Federal University of Bahia (EA/UFBA), Post Graduate MBA in Financial Management and Company (2006) by Post Graduate and Research Center at Visconde de Cairú (CEPPEV/FVC), Accountant ant Degree in Accounting Sciences (2004) by Estacio University Center of Bahia (Estacio/FIB) and is certified by IAFC First Degree in International Standards of Accounting-IFRS. Professor of Accounting and other courses like Administration and Engineering at UNIRB and also Course of Astronomy Institute of Physics from Federal University of Bahia (IF/UFBA). Experienced as a Tax Analyst and is also a musician and amateur astronomer enrolled in the Association of Amateur Astronomers of Bahia (AAAB). His publications of Accounting area have appeared in many websites specializing in tax and international accounting standards-IFRS. He is author of the Blog www.contabeisufba.blogspot.com and his research in the accounting area also made him the creator of New Accounting Policy, recently published in the Brazilian Journal of Accounting $(\mathrm{RBC})$, the most important publication in Brazil in this area.

In the area of Astronomy he has made presentations in numerous symposia and conferences in Brazil on the main university, Venezuela, Germany, USA and had his research also published in Spain. He is author of the Blog veraodabahia.blogspot.com read in over 90 countries and in more than 50 languages. He is also author of the book "The Solar Zenith Theory" (in Portuguese "A Teoria do Zênite Solar") published by Editors of Federal University of Bahia (EDUFBA) also released in English in Berlin. His research in the Astronomy area helps to create a Tropical Astronomy and new four seasons of the year for tropical zone.

*Corresponding author.

E-mail address: sampaioathayde@ yahoo.com.br 